\title{
Comparison of the Methods of Graphical Solution of Symbolic Sensitivity
}

\author{
Bohumil Brtnik \\ Department of Electrical Engineering \\ University of Pardubice \\ 53002 Pardubice Czech Republic \\ bohumil.brtnik@upce.cz
}

\author{
David Matousek \\ Department of Electrical Engineering \\ University of Pardubice \\ 53002 Pardubice Czech Republic \\ david.matousek@upce.cz
}

\begin{abstract}
Signal-flow graph (SFG) technique is a very useful tool for a hand analysis of a small and mediumsize networks and/or subnetworks of large systems. Last days, the SFG's have been effectively used for the sensitivity solutions, too. This paper describes the comparison between two graph methods for derivation transfer function: the nullor modified Coates flow graph symbolic analysis and the transformation graphs for symbolic analysis. As is given, in some cases the transformation graphs are more useful thanks to their clarity than standard solving methods.
\end{abstract}

Keywords-nullor model; modified Coates graph; transformation graph; sensitivity analysis.

\section{INTRODUCTION}

Symbolic circuit analysis is not a very popular method of circuit solving because its capacity is viewed as relatively limited. A useful extension is to add a sensitivity analysis feature [1].

In general, most sensitivity analysis techniques require input as a transfer function that can be obtained by performing linear algebraic or graph operations. Several symbolic techniques have been developed to derive analytical expressions or to transform certain characteristics of a linear network [2], [3], [4], [5], [6], [7], [8]. Generally, the analytical sensitivity analysis would be much easier by using a symbolic approach than a numerical approach where computation cost is a key concern.

\section{NULLOR MODIFIED COATES FLOW GRAPH SyMBOLIC SENSITIVITY ANALYSIS METHOD}

Nullor-based models have been created with respect to the ideal behavior of the active devices [9]. In this case, an analogue network can be modelled with nullors and impedances. In the next step, a reduction of the nullor circuit complexity is implemented and some transformations of the initial modified Coates flow-graph are realized to the following rules:

Rule \#1: When a node $\mathrm{k}$ in the nullor circuit is connected to the common node by a norator, all incoming edges including the self-loop in vertex $\mathrm{k}$ are removed in the corresponding flow-graph.

Rule \#2: When a node $\mathrm{k}$ in the nullor circuit is connected to the common node by a nullator, all outgoing edges including the self-loop in vertex $\mathrm{k}$ are removed in the corresponding flow-graph.

Rule \#3: When norator is connected between a pair of nodes $\mathrm{k}$ and $\mathrm{l}$ in the nullor circuit, the ends of all incoming edges into vertex $\mathrm{k}$, including the self-loop in vertex $\mathrm{k}$, are moved to vertex 1 in the corresponding flow-graph.

After we perform these rules, some vertices are incident with only incoming or outgoing edges and the $\mathrm{I}_{\mathrm{i}}^{\text {th }}$ vertex has to be united to the undetermined outgoing $(n-1)^{\text {th }}$ vertex or the next determined $n^{\text {th }}$ vertex.

A circuit example of the second-order high-pass filter, taken from [10], is shown in Fig. 1a to illustrate the described method. The equivalent nullor circuit $\mathrm{N}$ is composed and shown in Fig. 1b. An initial graph for the modified Coates flow graph (MCFG) for the part of the network is shown in Fig. 1c. After applying the rule of modification, the modified Coates flow graph follows, represented in Fig. 1d. Final graph after performing the rules for incoming branches is shown in Fig. 1e.

The voltage transfer function $\mathrm{T}_{\mathrm{ba}}(\mathrm{s})$ is given by Mason's formula (1) and the normalized sensitivity for this example $\mathrm{S}_{\mathrm{Y}_{1}(\mathrm{~s})}^{\mathrm{T}_{\mathrm{b}}(\mathrm{s})}$ is given by (2) [11]:

$$
\begin{gathered}
\mathrm{T}_{\mathrm{ba}}(\mathrm{s})=\frac{\sum \mathrm{p}_{(\mathrm{i})} \cdot \Delta_{(\mathrm{i})}}{\mathrm{V}-\sum \mathrm{S}^{(\mathrm{k})} \cdot \mathrm{V}^{(\mathrm{k})}} \\
\mathrm{S}_{\mathrm{Y}_{1}(\mathrm{~s})}^{\mathrm{T}_{\mathrm{a}}(\mathrm{s})}=\frac{\mathrm{Y}_{1}(\mathrm{~s})}{\mathrm{T}_{\mathrm{ba}}(\mathrm{s})} \cdot \frac{\partial \mathrm{T}_{\mathrm{ba}}(\mathrm{s})}{\partial \mathrm{Y}_{\mathrm{ji}}(\mathrm{s})} \cdot \frac{\mathrm{dY_{ \textrm {ji } }}(\mathrm{s})}{d \mathrm{Y}_{1}(\mathrm{~s})}
\end{gathered}
$$

\section{USING THE TRANSFORMATION GRAPH METHOD FOR SENSITIVITY ANALYSIS}

Another method for a circuit solution is a transformation graphs method [12]. This method requires neither equivalent circuit with nullors. The foundation of this method was given in [13], [14]. The transformation graph of an operational amplifier and differential operational amplifier [14] is shown in Fig. 2. 
In other words, the reduction of the number of nodes in the network is represented in this case very simply by the graphical rule by the transformation graph.

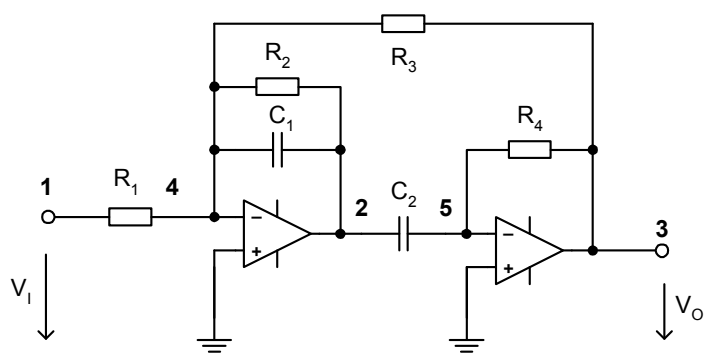

a)

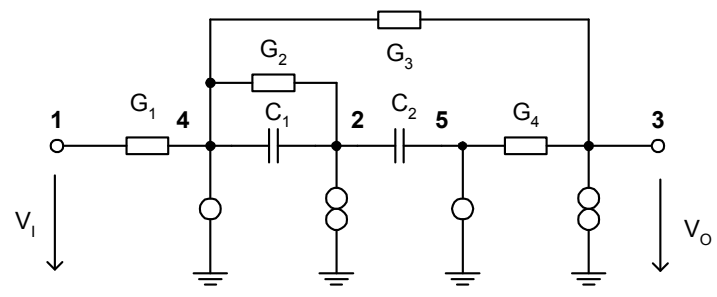

b)
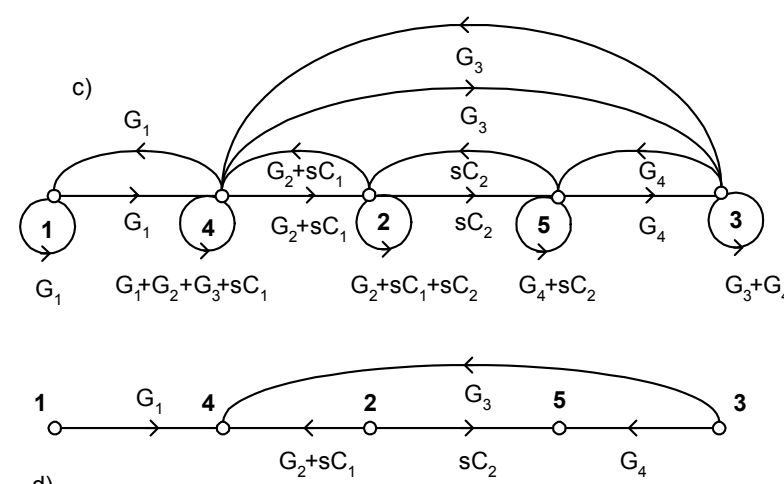

d)

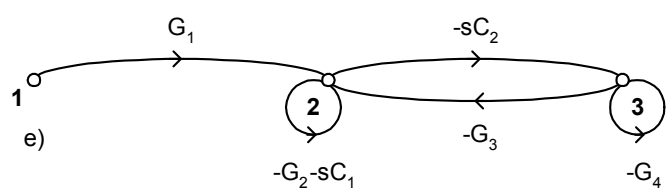

Figure 1. The second-order high-pass filter and its graph solution obtained by nullor modified method.

Estimation of the transformation graph is given by the simplest formula (3):

$$
\mathrm{Y}=\mathrm{a}^{\mathrm{I}} \cdot \tilde{\mathrm{Y}} \cdot \mathrm{a}^{\mathrm{V}} \cdot \alpha
$$

where $\tilde{Y}$ is the member of the initial Coates graph, Y is the member of the transformed graph.

For comparison, the same circuit will be solved by this method.

In the first step, the network must be drawn, as is realized in Fig. 3a. In the second step, an initial Coates flow graph is shown in Fig. 1b. In the next step, the transformation graph of the operational amplifier is drawn between corresponding nodes.

The result, i.e. transformed graph is in Fig. 3c. The voltage transfer function $\mathrm{T}_{\mathrm{ba}}(\mathrm{s})$ is given by Mason's formula (1) and the normalized sensitivity $\mathrm{S}_{\mathrm{Y}_{1}(\mathrm{~s})}^{\mathrm{T}_{\mathrm{ba}}(\mathrm{s})}$ is given by (2) from the transformed graph, as well in part II.<smiles>C#CCC1CC2CC(O[Al])C(C2)C1O[Al]</smiles>

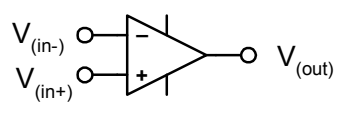
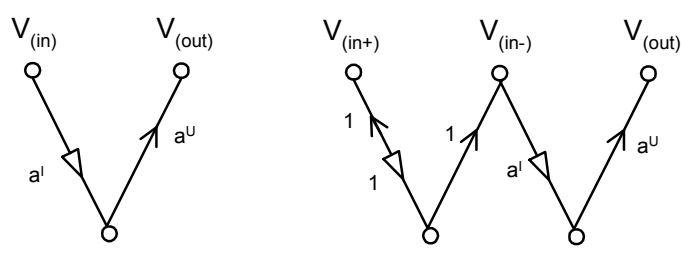

Figure 2. Transformation graphs of operational amplifiers.
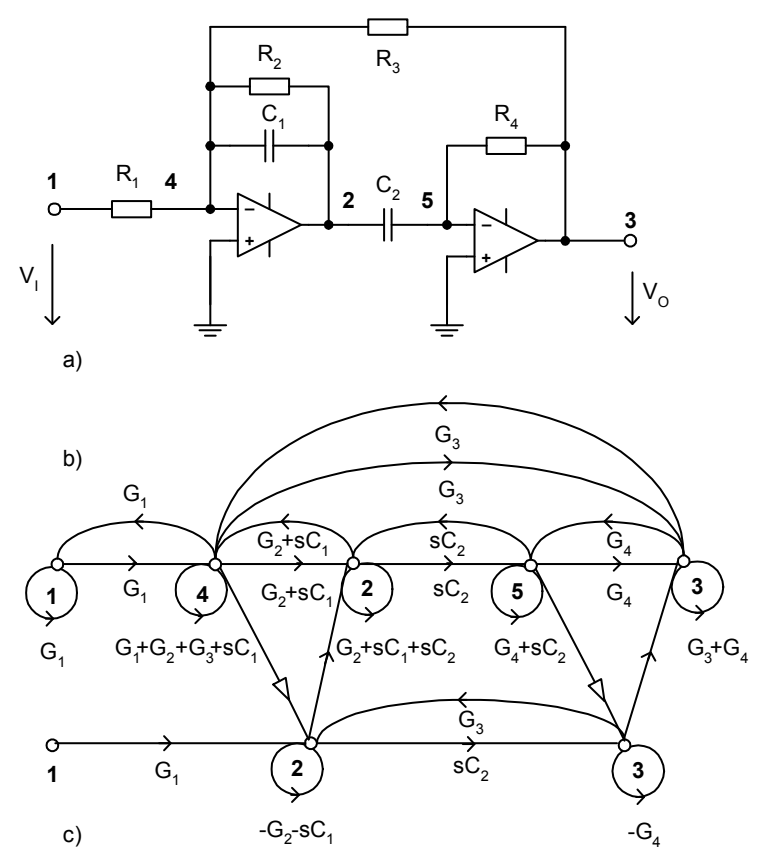

Figure 3. The second-order high-pass filter and its graph solution.

\section{USING THE SIMPLIFIED INVERTING AMPLIFIER GRAPH FOR SENSITIVITY ANALYSIS}

An operational inverting amplifier from Fig. 4a can be described by the Mason-Coates graph by the very known method [12], [13], [14], as is depicted in Fig. 4b.

The graph can be described by the set of equations (4), where the first eq. described branches going into the node $\mathrm{V}_{\mathrm{i}}$, and the second one branch going into the node $\mathrm{V}_{2}$.

$$
\begin{aligned}
& \left(\mathrm{G}_{1}+\mathrm{G}_{2}\right) \cdot \mathrm{V}_{\mathrm{i}}=\mathrm{G}_{1} \cdot \mathrm{V}_{1}+\mathrm{G}_{2} \cdot \mathrm{V}_{2} \\
& 1 \cdot \mathrm{V}_{2}=-\mathrm{A} \cdot \mathrm{V}_{\mathrm{i}}
\end{aligned}
$$


From the second equation is: $\mathrm{V}_{\mathrm{i}}=\frac{1}{-\mathrm{A}} \cdot \mathrm{V}_{2}$, after substitution into the first equation, will be where operational amplifier has infinity amplification factor:

$$
\begin{aligned}
& \left(G_{1}+G_{2}\right) \cdot \frac{1}{-A} \cdot V_{2}=G_{1} \cdot V_{1}+G_{2} \cdot V_{2} \\
& {\left[\left(G_{1}+G_{2}\right) \cdot \frac{1}{-A}-G_{2}\right] \cdot V_{2}=G_{1} \cdot V_{1}} \\
& \lim _{A \rightarrow \infty}\left[\left(G_{1}+G_{2}\right) \cdot \frac{1}{-A}-G_{2}\right] \cdot V_{2}= \\
& =-G_{2} \cdot V_{2}=G_{1} \cdot V_{1}
\end{aligned}
$$

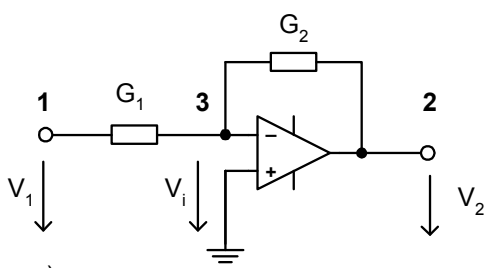

a)
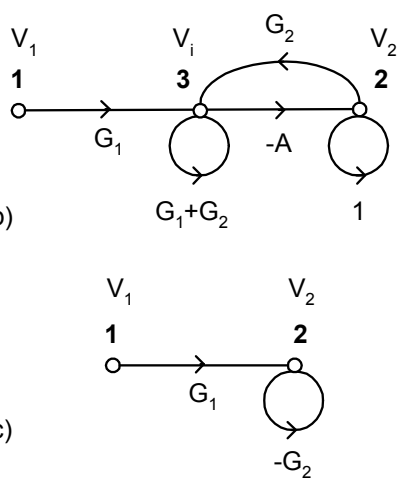

Figure 4. Inverting amplifier, its MC-graph and graph after simplification.

Graph of the equitation (7), i.e. simplified inverting amplifier graph $-\mathrm{G}_{2} \cdot \mathrm{V}_{2}=\mathrm{G}_{1} \cdot \mathrm{V}_{1}$ is depicted in Fig. 4c. Thus, the full-graph solution of the circuit from Fig. $5 \mathrm{a}$ is in Fig. $5 \mathrm{~b}$.

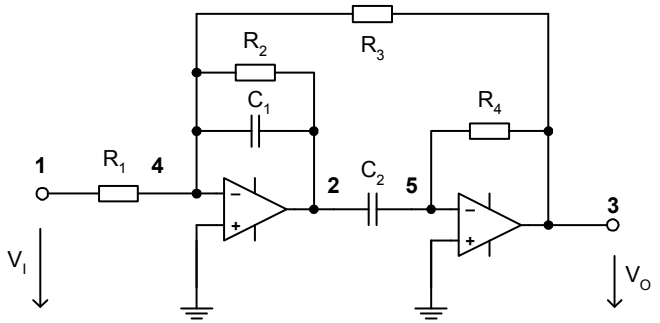

a)

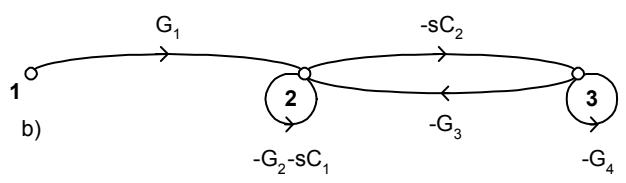

Figure 5. Full graph solution with simplified inverting amplifier graph.
The voltage transfer function $\mathrm{T}_{\mathrm{ba}}(\mathrm{s})$ is given by Mason's formula (1) and the normalized sensitivity $\mathrm{S}_{\mathrm{Y}_{1}(\mathrm{~s})}^{\mathrm{T}_{\mathrm{a}}(\mathrm{s})}$ is given by (2) from the transformed graph, as well in part II.

For example, we calculate sensitivity $\mathrm{S}_{\mathrm{G}_{\mathrm{V}}}^{\mathrm{F}_{\mathrm{V}}}$

$$
\begin{aligned}
& S_{G_{V}}^{F_{V}}=\frac{G_{2}}{F_{V}} \cdot \frac{\partial F_{V}}{\partial y_{22}} \cdot \frac{\partial y_{22}}{\partial G_{2}}= \\
& =\frac{G_{2}}{\frac{G_{1} \cdot s C_{2}}{-G_{4} \cdot\left(-G_{2}-s C_{1}\right)-s C_{2} \cdot s C_{2}}} \\
& \cdot \frac{G_{1} \cdot\left(-G_{4}\right)}{-G_{4} \cdot\left(-G_{2}-s C_{1}\right)-s C_{2} \cdot s C_{2}} \cdot \\
& \cdot \frac{s C_{2} \cdot 1}{-G_{4} \cdot\left(-G_{2}-s C_{1}\right)-s C_{2} \cdot s C_{2}} \\
& \cdot \frac{\partial\left(-G_{2}-s C_{1}\right)}{\partial G_{2}}=\frac{G_{2} \cdot G_{4}}{G_{4} \cdot\left(G_{2}+s C_{1}\right)-s C_{2} \cdot s C_{2}}
\end{aligned}
$$

\section{CONCLUSION}

As can be seen by comparison of Fig. 1 and Fig. 3, namely Fig. 1e and Fig. 3c, the resulting graphs are identical. However, a clearly arranged set of transformation graphs (see Fig. 2) gives a much clearer solution. Thanks to its clarity, the graph method is a more suitable for a calculation of the sensitivity. This method requires neither equivalent circuit with nullors, i.e. nor auxiliary network transformation into nullors circuit (i.e. nor other rules for these transformations), nor rules for transformation a nullor circuit into Coates graph, and nor rules for modification Coates graph into modified Coates graph.

As can be seen from Tab. 1, the transformation graph method requires fewer special rules and fewer steps. The sensitivity calculation is both challenging in both cases by (1) and (2). It is not listed in this paper for comparison, its foundation was given in [9] in detail.

\section{TABLE I. COMPARISON OF BOTH METHODS}

\begin{tabular}{|l|c|c|}
\hline Method & Main rules & Steps \\
\hline Nullor models & 4 & 5 \\
\hline Transformation graph & 1 & 4 \\
\hline Inverting amplifier graph & 1 & 1 \\
\hline
\end{tabular}

The goal of the article was not a calculation of the sensitivity, but a comparison of some variants of the calculation. As is shown, the method of transformation graphs is, in some cases (one of which was described), much preferable and advantageous than the method based on nullor models.

However, the simplified inverting amplifier graph method looks as the best, because it is the easiest, remembering the chart of the inverting amplifier is very easy, because it is logical. Feedback elements are 
drawn to their own loop, input elements are drawn to the input branch.

Graph methods will probably continue to be an effective way of solving electrical circuits [1], [2], [15].

\section{REFERENCES}

[1] G. Shi, W. Chen, C. J. R. Shi, "A Graph Reduction Approach to Symbolic Circuit Analysis", in Proc. Asia South-Pacific Design Automation Conference (ASPDAC), Yokohama, Japan, Jan. 2007, pp. 197-202.

[2] G. Shi, "Graph-Pair Decision Diagram Construction for Topological Symbolic Circuit Analysis", IEEE Transactions on Computer-aided Design of Integrated Circuit and systems" vol. 32, no. 2, Feb. 2013, pp. 275-288.

[3] M. Pirzachala, M. Fakhfakh, "Transformation of LC-filters to Active RC-circuits wia the Two-graph Method", Microelectronics Journal, vol. 42, no. 8, Aug. 2011, pp. 9991005.

[4] S. Rodriguez-Chavez, A. A. Palma-Rodriguez, E. TleloCuautle, S. X. -D. Tan, "Graph Based Symbolic and Symbolic Sensitivity Analysis of Analog Integrated Crcuits", Analog/RF and Mixed-Signal Circuits Systematic Design, Springer, Lecture Notes in Electrical Engineering, vol. 233, 2013, pp. 101-122.

[5] M. Iordache, L. Dumitruu, D. Niculae, "On the Sensitivity Analysis of Analog Circuits", Annals of the University of Craiova, Electrical Engineering series, 2008, No. 32, pp. 11-16.

[6] P.M. Li, Sensitivity, "Analysis of Large Linear Networks Using Symbolic Programs", Proceedings of The IEEE International Symposium on Circuits and Systems ISCAS '92, 10-13 May 1992, vol. 3, pp. 1145-1148.
[7] J.-F. Mao and E. S. Kuh, "Fast Simulation and Sensitivity Analysis of Lossy Transmission Lines by the Method of Characteristics", IEEE Trans.Circuits and Systems I: Fundamental Theory and Applications, vol. 44, iss. 5, May 1997.

[8] S. Osowski, "Signal flow graphs for determination of higher order sensitivities of circuit functions", Proceedings of the European Conference on Circuits Theoryand Design. 2011, pp. $446-449$

[9] I. N. Asenova, "Calculation of First-, Second-Order and Multiparameter Symbolic Sensitivity of Active Circuits by using Nullor-Model and Modified Coates Flow Graph", International Jourmal of Microelectronics and Computer Science, vol. 2, no. 4, 2011, pp. 129-135.

[10] F. Balik, B. Rodanski, "Calculation of First-, Second-Order and Symbolic Sensitivities in Sequential Form via the Transimpedance Method", proceedings ECCTD'99, 1999, pp. 70-73.

[11] I. N. Asenova, F. Balik, "Multiparameter Symbolic Sensitivity Analysis Enhanced by Nullor Model and Modified Coates Flow Graph", Theoretical and Applied Electrical Engineering, vol. 11, no. 2, 2013, pp. 108-114.

[12] T. Dostal, "The Analysis of the Active Components Containing Switched Capacitors by Nodal Voltage Method". Electronics horizont, 1984, 45, no. 1, pp. 21-26. (in Czech).

[13] J. Čajka, "The Circuits Theory. Linear Circuits", SNTL/ALFA, Prague, 1979.

[14] J. Mikula, T. Dostal, "A Design Approach to capacitorswitched Networks, Using MC Graphs", Electronics horizont, vol. 46 , no. 12,1985 , pp. 560-565.

[15] G. A. Nenov. A comparative study on symbolic network sensitivity analysis by using some kinds of signal-flow graphs. In Proceedings of the 5th International conference on circuits, system, control, signals (CSCS'14). 2014, Salerno, Italy, p. 54-63. 